\title{
We Hommage à Hugues Liborel-Pochot
}

\section{\$ Mémoire, Histoire, Oubli. Le Travail d'Histoire et/ou de Mémoire}

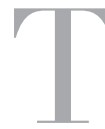

out au long de l'exposition Les Anneaux de la Mémoire au château des Ducs de Bretagne à Nantes (1992-1994) le public nantais et d'ailleurs a manifesté son intérêt pour l'approche historique des questions soulevées par la traite atlantique, l'esclavage et les héritages légués. L'association des Anneaux de la Mémoire décida de poursuivre cette démarche. Mais quel était le sens d'une telle volonté ? Pouvait-on considérer que la page était tournée, que les comptes étaient soldés et qu'il n'y avait plus qu'à enterrer le sujet dans des monuments commémoratifs, comme on enterre un mort que l'on vient honorer régulièrement et rituellement pour garder le souvenir du défunt désormais disparu?

On n'enterre pas la mémoire comme nous enterrons nos morts. Elle reste vivante et se transmet telle une onde de choc qui ne faiblit pas obligatoirement avec le temps, mais qui risque toujours d'accumuler de nouvelles énergies destructrices si on la néglige. La traite négrière a été un phénomène collectif considérable qui a participé à la construction du monde atlantique, dans la violence et l'humiliation. Les morts qui ont subi la violence se sont tus avec leurs souvenirs, mais l'humiliation demeure. Elle reste en mémoire comme un trauma. Dans son ouvrage La Mémoire, l'Histoire, l'Oubli (Seuil, 2000), Paul Ricoeur, évoquait les « traumatismes collectifs et les blessures de la mémoire collective " que seul " le travail d'histoire dont la théorie reste à faire » permet de résoudre. Il proposait de combattre ainsi la surprenante réapparition de conflits sociaux et de forces politiques qui semblaient ressurgir d'une époque désormais révolue.

C'est aussi cette méthode qui avait rassemblé dès 1999 le comité de rédaction des Cahiers des Anneaux de la Mémoire. Des historiens d'abord, mais aussi des anthropologues, des psychanalystes et des juristes de diverses nationalités se sont rassemblés à l'initiative d'Hugues Liborel-Pochot, psychanalyste guadeloupéen comme il aimait se présenter et d'Olivier Douville, psychanalyste et directeur de publication de la revue Psychologie Clinique. La conviction que Paul Ricoeur avait acquise dans sa recherche philosophique était la même que celle qu'avaient acquise ces thérapeutes 
par l'expérience clinique. Depuis la publication du premier numéro, ce sont plus de 200 chercheurs et surtout des historiens d'Europe, d'Afrique, des Amériques et de l'Océan Indien qui ont soutenu cette démarche. En offrant leurs travaux et leur collaboration à chaque édition des Cahiers, ils ont permis à l'association des Anneaux de la Mémoire de continuer à défricher le vaste champ méconnu du travail d'histoire et/ ou de mémoire par le récit historique à la hauteur de la complexité des phénomènes historiques. Car la morale qui sélectionne les coupables avec ses confessionnaux où l'on distribue les rôles de confesseur ou de confessé ne suffit pas pour apprendre et comprendre ce qui s'est réellement passé et pourquoi il en fut ainsi. Nos sociétés d'Europe, d'Afrique et des Amériques qui furent concernées par la traite négrière et l'esclavage ont besoin d'autre chose pour sortir de ce qu'il faut bien appeler un trauma. Et même si ce crime collectif ne fut pas le seul dans toute l'histoire de l'humanité, loin s'en faut, il eut cependant sa spécificité. Il n’y a pas de compte à solder avec l'histoire. Par contre il reste beaucoup de connaissances à acquérir pour comprendre comment le monde atlantique, édifié sur des désastres humains qui ne peuvent être oubliés, a aussi fait émerger des sociétés originales, construites sur le fracas non seulement des langues mais aussi des civilisations... à condition bien entendu que l'on veuille admettre qu'il s'agissait de civilisations à part entière. En effet, si le processus de la traite atlantique pour le développement du Nouveau Monde est un crime collectif de plus dans l'histoire de l'humanité et qu'il faut assumer, c'est aussi un processus de créolisation des civilisations atlantiques qu'il faut comprendre pour l'avenir, et dont la théorie reste à faire elle aussi. Cette théorie n'est pas nouvelle. Elle a émergé progressivement parmi les chercheurs et les poètes qui furent à l'avant-garde de la réflexion à partir de leur expérience. On commence à comprendre que ce processus n'est pas réservé à la seule rencontre entre Européens et Africains, mais qu'il date de longtemps et qu'il est universel.

Jusque dans les dernières semaines de sa vie, Hugues Liborel-Pochot s'est efforcé de participer à cette vaste réflexion en collaborant activement au projet de la prochaine édition des Cahiers des Anneaux de la Mémoire, le numéro 15 qui aura pour titre : "Créolités aux Amériques françaises ». Nous avons beaucoup appris de son expérience et de ses enseignements. Il peut désormais reposer en paix.

Jean-Marc Masseaut Directeur de Rédaction des Cahiers des Anneaux de la Mémoire Vice-président des Anneaux de la Mémoire 